15

\title{
Шаблонный синтез микроструктур железа на основе трековых мембран
}

\author{
(C) В.Г. Семенов ${ }^{1}$, С.А. Бедин ${ }^{2,3}$, В.Е. Асадчиков ${ }^{2}$, А.Б. Васильев ${ }^{2, \text { ฯ }}$ \\ ${ }^{1}$ Институт химии Санкт-Петербургского государственного университета, \\ Санкт-Петербург, Петергоф, Россия \\ ${ }^{2}$ Институт кристаллографии им. А.В. Шубникова ФНИЦ \\ „Кристаллография и фотоника“ РАН, Москва, Россия \\ ${ }^{3}$ Московский педагогический государственный университет, Москва, \\ Россия \\ ๑ E-mail: vasiliev51@mail.ru
}

Поступило в Редакцию 21 февраля 2018 г.

Получены железные нанопроволоки методом шаблонного синтеза на основе полимерных трековых мембран, что является необходимым этапом отработки синтеза регулярных металлических микроструктур. Методом растровой электронной микроскопии изучена топография их поверхности. Для исследования локального состояния атомов железа использована мессбауэровская спектрометрия.

DOI: 10.21883/PJTF.2018.14.46346.17262

Получение ориентированных металлических острийных микроструктур представляет интерес для создания систем управления излучением оптического и рентгеновского диапазонов, элементов устройств хранения информации и т.д. [1-4]. Если такая двумерная микроструктура состоит из магнитного материала (железа, никеля, кобальта или их сплавов), то благодаря сильной анизотропии формы она приобретает одноосную магнитную анизотропию, что обусловливает возможность ее использования в качестве элемента памяти [5]. Оригинальным методом создания таких микроструктур является шаблонный синтез с применением трековых мембран (ТМ). ТМ отличаются правильной (обычно цилиндрической) формой пор, определенным их числом на единицу площади и рекордно узким разбросом диаметров [6]. Были исследованы особенности роста нанопроволок (НП) из железа в малых порах [7] и показано, что они преимущественно имеют поликристаллическую структуру, а при уменьшении диаметра их магнитные моменты стремят- 


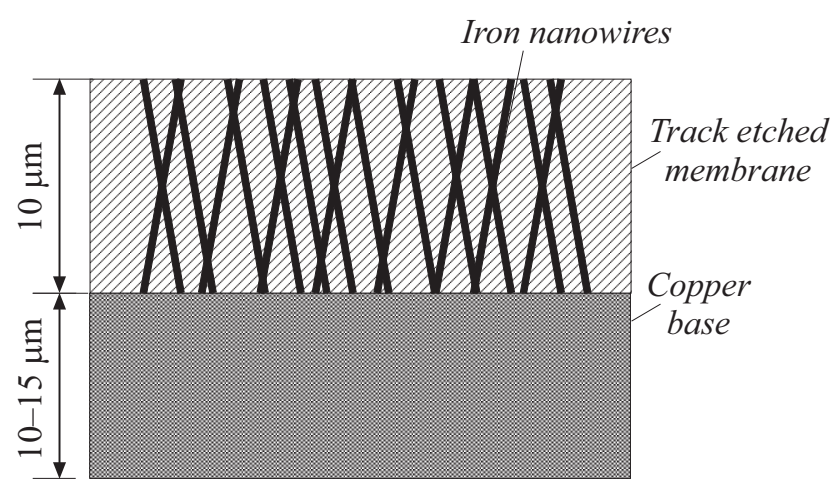

Рис. 1. Схема ТМ с порами, заполненными железом.

ся выстраиваться вдоль направления роста [8]. Важным достоинством магнитных наноструктур в полимерных мембранах является то, что возникает возможность изменять форму мембран, например сворачивая их в трубки или складывая их в стопки, создавать многослойные структуры. Одним из важнейших перспективных приложений может быть использование таких мембран в качестве рабочей среды в устройствах, предназначенных для высокоградиентной магнитной фильтрации [9].

Настоящая работа является необходимым шагом в создании регулярных металлических микроструктур, перспективных для различных приложений в оптике, а также для элементов магнитной памяти.

Исследуемые НП были изготовлены на основе ТМ из полиэтилентерефталата (ПЭТФ) с диаметром пор от 60 до $500 \mathrm{~nm}$ и толщиной 10-12 $\mu \mathrm{m}$. Синтез проводился методом электрохимического осаждения металла в поры ТМ при комнатной температуре по методике [8]. Схематически образец в разрезе представлен на рис. 1.

После заполнения пор ТМ металлом полимер был удален для дальнейшего исследования методом растровой электронной микроскопии (РЭМ). Традиционно ТМ из ПЭТФ удаляется путем растворения в концентрированном растворе щелочи $(6 \mathrm{~N} \mathrm{NaOH})$ при высокой температуре $\left(60^{\circ} \mathrm{C}\right)$. Однако в случае проволок из железа это приводит к их деградации в результате воздействия щелочи. Чтобы этого избежать, процесс удаления ТМ проводился в два этапа. На первом этапе ТМ с порами, заполненными железом, подвергались воздействию

$5^{*}$ Письма в ЖТФ, 2018, том 44, вып. 14 

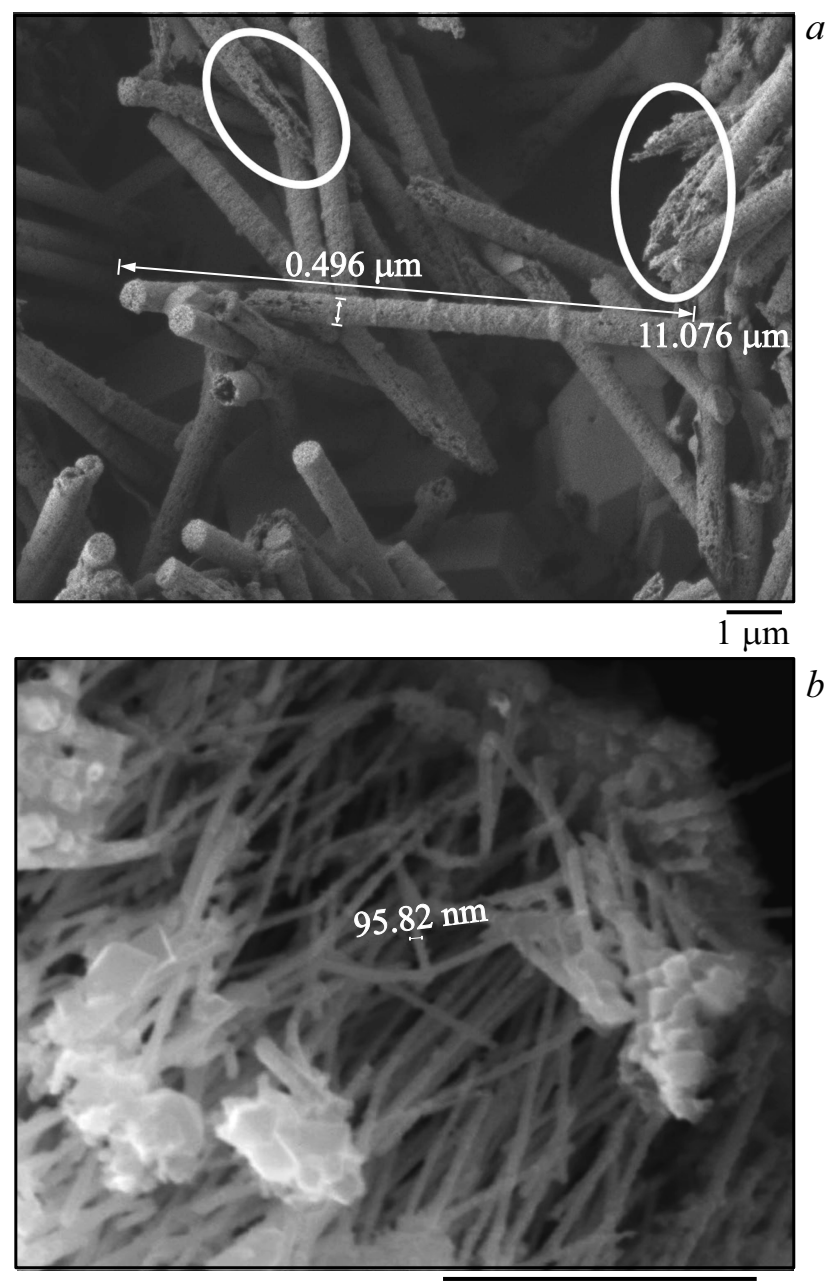

$3 \mu \mathrm{m}$

Рис. 2. РЭМ-изображение НП из железа диаметром $500 \mathrm{~nm}$ после традиционного травления полимера при высокой температуре $(a)$ и НП диаметром $100 \mathrm{~nm}$ после двухэтапного травления (облучение УФ и травление при комнатной температуре) $(b)$. 
УФ-излучения с длиной волны $310 \mathrm{~nm}$ в течение $50 \mathrm{~h}$. Это приводило к частичной деструкции полимера. Затем полимер травили в растворе щелочи $(6 \mathrm{~N} \mathrm{NaOH})$ при комнатной температуре в течение 3 h. На рис. 2 представлены электронно-микроскопические фотографии образцов НП из железа, полученные методом шаблонного синтеза. Использовался растровый электронный микроскоп JSM-7401F. На фотографиях хорошо видно различие поверхности НП после травления полимера в растворе щелочи при высокой температуре (рис. 2,a) и после двухэтапного травления (рис. $2, b$ ). На рис. 2, $a$ видно, что поверхность НП шероховатая. После же двухэтапного травления (рис. 2, $b$ ) поверхность проволок гладкая, на ней не наблюдается „изъеденных“ краев. Для исследования локальных состояний атомов железа в синтезированных структурах использовалась мессбауэровская спектроскопия (МС). Выбор метода определялся тем, что МС является абсолютно селективным по изотопу железа методом качественного и количественного анализа различных локальных окружений атомов железа. На основе данных МС можно не только определить наличие магнитной анизотропии, но и найти средний угол отклонения намагниченности структуры от нормали к поверхности мембраны. Дополнительным достоинством МС в отличие от рентгеновской дифракции является то, что она позволяет исследовать объекты в наноразмерном состоянии [10].

Мессбауэровские измерения проводились в геометрии пропускания на спектрометре фирмы WISSEL в режиме постоянных ускорений при комнатной температуре. В качестве источника гамма-излучения использовался ${ }^{57}$ Со в матрице родия. Измеряемые образцы были неподвижны и устанавливались таким образом, чтобы плоскость мембраны была перпендикулярна направлению гамма-излучения от источника. Такая геометрия позволила нам определять усредненную ориентацию намагниченности ансамбля острийных наноструктур в соответствии с известным соотношением между интенсивностями линий магнитной сверхтонкой структуры

$$
\frac{I_{2,5}}{I_{1,6}}=\frac{3\left(1+\left\langle\cos ^{2} \theta_{0}\right\rangle\right)}{5-3\left\langle\cos ^{2} \theta_{0}\right\rangle},
$$

где $I_{2,5} / I_{1,6}$ означает отношение интенсивностей второй и пятой линий магнитной сверхтонкой структуры мессбауэровского спектра к интенсивности первой и шестой, $\left\langle\theta_{0}\right\rangle-$ средний угол между направлением гамма-излучения и ориентацией намагниченности острийных наноструктур.

Письма в ЖТФ, 2018, том 44, вып. 14 

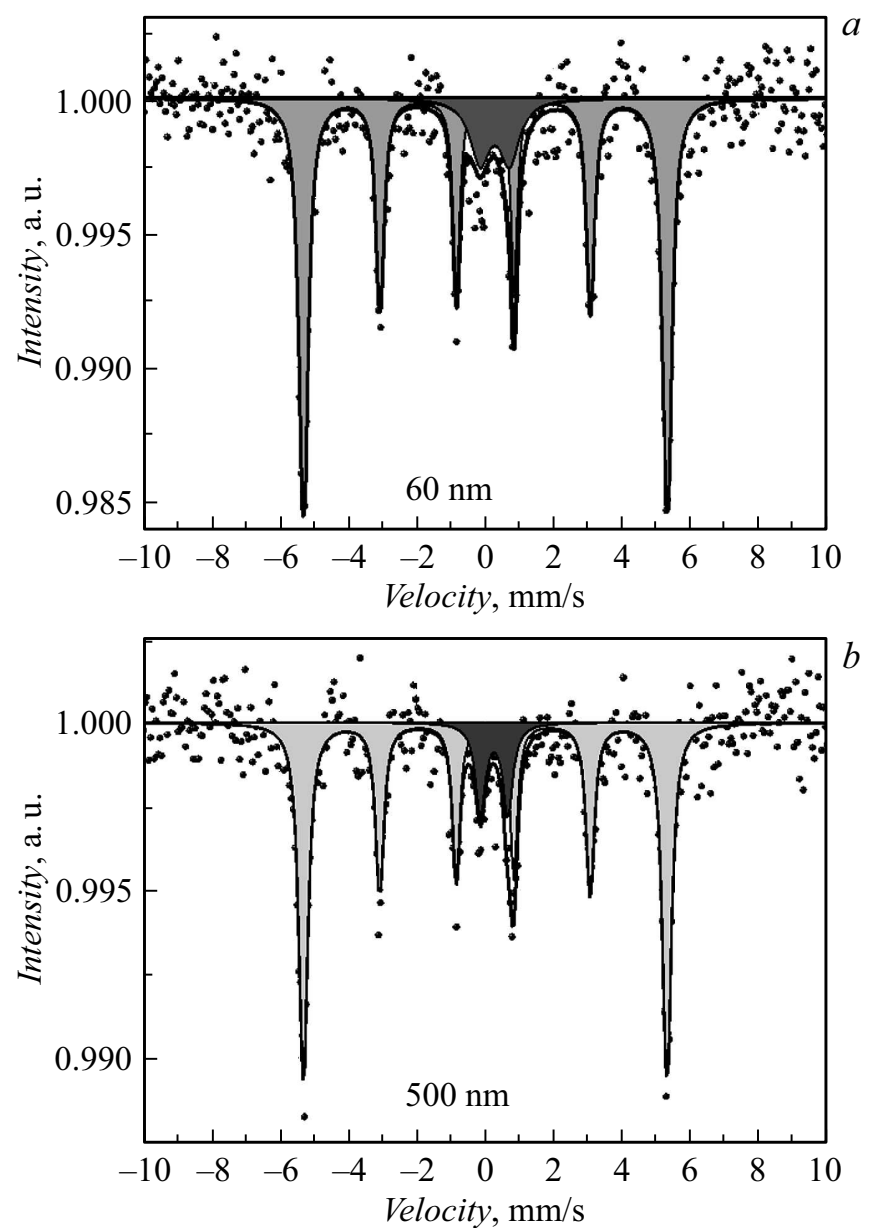

Рис. 3. Мессбауэровские спектры полученных нанопроволок диаметром 60 (a) и $500 \mathrm{~nm}(b)$.

На рис. 3 приведены мессбауэровские спектры и результаты их обработки.

Результаты обработки указывают на то, что спектры обоих образцов состоят из двух подспектров (см. таблицу), т. е. атомы железа находятся 
Мессбауэровские параметры (по результатам обработки экспериментальных спектров)

\begin{tabular}{c|c|c|c|c|c|c}
\hline $\begin{array}{c}\text { Номер } \\
\text { образца }\end{array}$ & $\begin{array}{c}\text { Диаметр, } \\
\text { пор, nm }\end{array}$ & $\begin{array}{c}\text { Вид под- } \\
\text { спектра }\end{array}$ & $\begin{array}{c}\text { Изомерный } \\
\text { сдвиг, mm/s }\end{array}$ & $\begin{array}{c}\text { Квадрупольное } \\
\text { pасщепление, } \\
\mathrm{mm} / \mathrm{s}\end{array}$ & $\begin{array}{c}\text { Доля } \\
\text { Магнитное } \\
\text { поле, T } \\
\text { желовеза, } \\
\%\end{array}$ \\
\hline 1 & 60 & Дублет & $0.26 \pm 0.03$ & $0.80 \pm 0.07$ & - & 14 \\
2 & 500 & Секстет & $0.00 \pm 0.00$ & $0.00 \pm 0.01$ & $32.99 \pm 0.045$ & 86 \\
& & Дублет & $0.28 \pm 0.08$ & $0.86 \pm 0.15$ & - & 16 \\
Секстет & $0.00 \pm 0.00$ & $0.00 \pm 0.01$ & $33.023 \pm 0.040$ & 84
\end{tabular}

в двух неэквивалентных окружениях. Одному окружению отвечает магнитно-упорядоченное состояние (секстет) с параметрами, соответствующими металлическому железу $\alpha$-Fe, второму окружению железо в немагнитной фазе (дублет). Выделенные в спектрах этих образцов компоненты, представленные в виде дублетов, отвечают за атомы железа, находящиеся в немагнитном состоянии (скорее всего, это атомы железа на торцах наностержней, провзаимодействовавшие с медной подложкой). Доля этих атомов не превышает 14\% для образца с диаметром пор $60 \mathrm{~nm}$ и $16 \%$ для образца с диаметром пор $500 \mathrm{~nm}$. На основании приведенного выше соотношения была получена величина угла $\theta \approx 43 \pm 1^{\circ}$. Возможно, наличие железа в немагнитном состоянии связано с присутствием в структуре НП водорода, который поглощается металлом, осаждаемым при комнатной температуре.

В работе получены НП из железа на медной подложке. Показано, что при удалении полимера в растворе щелочи происходит частичное растворение НП. Чтобы этого избежать, предложена методика двухэтапного удаления шаблона: обработка ультрафиолетом и последующее травление. Ее результативность подтверждается данными РЭМ.

Методом мессбауэровской спектроскопии показано, что полученные нанопроволоки обладают значительной анизотропией свойств. Эти результаты позволяют полагать, что метод шаблонного синтеза с применением трековых мембран может быть очень эффективным и высокотехнологичным для получения практически моноразмерных нанопроволок. Он дает возможность регулировать величину магнитной анизотропии, не только варьируя диаметр пор, но и меняя толщину

Письма в ЖТФ, 2018, том 44, вып. 14 
полимерной мембраны. Предлагаемый метод будет особенно актуален при использовании в качестве шаблона трековой мембраны с регулярной локализацией пор, направление которых перпендикулярно ее поверхности. Более того, открываются возможности применения таких микроструктур для различных приложений в оптике.

Работа частично выполнена на оборудовании ЦКП ФНИЦ „Кристаллография и фотоника“ РАН при поддержке Федерального агентства научных организаций (соглашение № 007-ГЗ/Ч3363/26).

Авторы выражают благодарность В.В. Артемову за получение электронно-микроскопических изображений.

\section{Список литературы}

[1] Горин Д.А., Ященок А.М., Кокшаров Ю.А., Невешкин А.А., Сердобиниев А.А., Григорвев Д.О., Хомутов Г.Б. // ЖТФ. 2009. Т. 79. В. 11. С. 113119.

[2] Губин С.П., Кокшаров Ю.А., Хомутов Г.Б., Юрков Г.Ю. // Успехи химии. 2005. T. 74. № 6. C. 539-574.

[3] Müller L., Käpplinger I., Biermann S., Brode W., Hoffmann M. // J. Micromech. Microeng. 2014. V. 24. P. 035014.

[4] Groß P., Esmann M., Becker S.F., Vogelsang J., Talebi N., Lienau C. // Adv. Phys.: X. 2016. V. 1. P. 297-330.

[5] Coey J.M.D. Magnetism and magnetic materials. Cambridge: Cambridge University Press, 2010. $625 \mathrm{p}$.

[6] Мчедлишвили Б.В., Березкин В.В., Васильев А.Б., Виленский А.И., Загорский Д.Л., Митерев А.М., Олейников В.А. // Кристаллография. 2006. Т. 51. № 5. C. 906-919.

[7] Baik J.M., Schierhorn M., Moskovits M. // J. Phys. Chem. C. 2008. V. 112. P. 2252-2255.

[8] Фролов К.В., Загорский Д.Л., Любутин И.С., Коротков В.В., Бедин С.А., Сульянов С.Н., Артемов В.В., Мчедлишвили Б.В. // Письма в ЖЭТФ. 2014. T. 99. B. 10. C. $656-663$.

[9] Гусев Б.А., Семенов В.Г., Панчук В.В. // ЖТФ. 2016. Т. 86. В. 13-19.

[10] Семенов В.Г., Москвин Л.Н., Ебимов А.А. // Успехи химии. 2006. Т. 75 . № 4. C. 71-83. 